\title{
AC 2008-1018: FORMATIVE EVALUATION OF A PROFESSIONAL DEVELOPMENT PROGRAM FOR HIGH SCHOOL TEACHERS INFUSING ENGINEERING DESIGN INTO THE CLASSROOM
}

\section{Jodi Cullum, Utah State University}

Jodi Cullum is a doctoral student in the Experimental and Applied Psychology program at Utah State University. Her interests lie in outcomes research in health psychology and program evaluation more broadly. Jodi has been involved in numerous small-scale research studies in Canada and the United States as well as large-scale national projects. She has been involved in STEM evaluation for the National Center for Engineering and Technology Education since May 2007.

\section{Christine Hailey, Utah State University}

Christine E. Hailey is a Professor and Senior Associate Dean in the College of Engineering at Utah State University. She is Director of the National Center for Engineering and Technology Education, an NSF-funded Center for Learning and Teaching. She is a member of the ADVANCE-US team, an NSF-funded program to address issues that impact female faculty's effectiveness and satisfaction in the four engineering and science colleges at Utah State.

\section{Daniel Householder, Utah State University}

Daniel L. Householder is Co-Principal Investigator of the National Center for Engineering and Technology Education and holds visiting professorships in the College of Engineering at Utah State University and the College of Technology at Purdue University. He has been a program officer at the National Science Foundation and recently served as PI of an Advanced Technological Education project based at Hofstra University. He is a former faculty member at Iowa State University, Texas A\&M University, and the University of Illinois; and taught in the public schools of New Jersey, Illinois, and North Carolina. He has served as president of the International Technology Education Association, president of the Council on Technology Teacher Education, and chair of the Mississippi Valley Technology Teacher Education Association.

\section{Chris Merrill, Illinois State University}

Chris Merrill is an Associate Professor and serves as the Technology Education Program Coordinator in the Department of Technology at Illinois State University. Merrill has taught technology education since 1992 at both the high school and university levels. Currently, Dr. Merrill is a Co-Pi at ISU on the National Center for Engineering and Technology Education, and serves as both a PI and Co-PI on four separate Department of Education Mathematics and Science Partnership grants.

\section{James Dorward, Utah State University}

James Dorward is a Professor of Elementary Education and Associate Dean for Research in the College of Education and Human Services at Utah State University. 


\section{Formative Evaluation of a Professional Development Program for High School Teachers Infusing Engineering Design into the Classroom}

\section{Introduction}

Engineering as a recognized elementary and secondary school subject within the United States has recently received attention from the science, technology education and engineering communities. Benchmarks for Science Literacy includes "the designed world" as a standard. ${ }^{1}$ Engineering design is directly addressed by four of the 20 Standards for Technological Literacy. ${ }^{2}$ The American Society for Engineering Education (ASEE) has launched a large K-12 effort to make engineering concepts more accessible to teachers, students and parents [http://www.engineering12.org]. The establishment of the K-12 and Pre-College Engineering Division of ASEE in 2004 was a significant event in the development of engineering as a subject for K-12.

For engineering to emerge as a recognized primary and secondary school subject, a number of questions must be addressed, including:

- What are the most important engineering concepts and skills that students of differing interests and aptitudes should master?

- What instructional practices are necessary for effective teaching of engineering to diverse student populations?

- What are the most effective practices for assessing student understanding and skills?

- What teacher professional development and pre-service programs are needed for implementing effective engineering education curriculum, teaching and assessment?

The National Center for Engineering and Technology Education (NCETE) is addressing many of these questions in its role as a National Science Foundation Center for Learning and Teaching. The Centers for Learning and Teaching (CLT) aim to enrich and diversify the national infrastructure for instruction in K-12, undergraduate and graduate education in science, technology, engineering and mathematics (STEM). Each center focuses on a particular set of nationally significant issues related to STEM education. NCETE is a CLT composed of a collaborative network of scholars with backgrounds in technology education, engineering and related fields. Its mission is to build capacity in technology education and to improve the understanding of the learning and teaching of all high school students and teachers as they apply engineering design processes to technological problems. One of the NCETE capacity-building thrusts is professional development. NCETE strives to enhance national capability by generating 
knowledge and tools that can be used to further effective professional development developing a cadre of professional development leaders.

In 2004 through 2006, NCETE developed and evaluated five site-specific professional development (PD) programs on the infusion of engineering design into high school classrooms. These workshops involved high school teachers in California, Illinois, North Carolina, Utah and Wisconsin. ${ }^{3-6}$ Traditional professional development programs in technology education have been characterized by short-term workshops conducted by professional developers with little or no follow-up and unknown levels of classroom implementation. In an attempt to provide a richer milieu for change, each of the sites developed and delivered over 100 hours of professional development each year to technology teachers and in some instances to mathematics and science teachers as well. Most sites utilized faculty teams from engineering, technology teacher education, and mathematics and science education to design and deliver the year-long PD experience. Given the exploratory nature of these programs, only a small number of teachers could be selected for participation. The five sites delivered professional development to a total of 115 teachers, 24 of whom were female and 17 of whom represented ethnic minorities (6 were female, ethnic minorities).

In the summer of 2007, a one-week workshop involving professional development providers, exemplary teachers who had experienced one of the NCETE site-specific PD programs, beginning teachers, high school students and evaluators reflected on their experiences in an attempt establish the characteristics of an effective PD program for high school teachers who are seeking to infuse engineering design concepts into STEM classroom. This paper reports the responses from participants in this unique workshop session.

\section{Background}

The emergence of engineering as a school subject is in its infancy. The most important engineering concepts and skills that students of differing interests and aptitudes should master are not well defined. State adopted curriculum materials, often the cornerstone of a professional development program, are still unavailable. To begin to understand the important features of an effective professional development program, NCETE focused its efforts on engineering design as a content area in high schools. The rationale for this decision is that aspects of engineering design are shared by technology design as described in standard 8 of the Standards for Technological Literacy. ${ }^{7}$ One area of commonality is rough agreement on a general design procedure including problem clarification, generation of possible solutions, evaluation of possible solutions, deciding on a solution, and representing and detailing it. ${ }^{8}$ As noted by Theodore Lewis, ${ }^{8}$ there are also regions of divergence. 
Beyond areas of commonality is a zone of divergence, beginning with assumptions about the knowledge base required by the design engineer. It is evident that engineering designers must possess a combination of scientific, mathematical, and domain-specific knowledge. In addition they must possess engineering design content knowledge, consisting of prior experience, knowledge of heuristics, ability to work within tight constraints, ability to make trade-offs, ability to change design in the course of a project, ability to design for manufacturability, and ability to conform to the needs of a customer. (p. 44)

It is important to note that although there is the zone of divergence, in many instances technology educators are already providing many important aspects of engineering design content in high schools. Technology education classrooms and laboratories provide students with opportunities to work on ill-structured problems in realms of energy, construction, manufacturing, communication and transportation. ${ }^{9}$ Lewis notes that "students learn how to make trade-offs, to consider safety factors, to understand customer needs, to arrive at the right tooling and to make decisions about appropriate processes. In these classrooms, many will in fact be rehearsing in outlines, what it means to be an engineer." (p. 849)

One of the challenges in designing and evaluating effective PD programs for teachers interested in infusing engineering design into high school classrooms is to understand and acknowledge relationships between science, technology, engineering and mathematics (STEM) education. Much has been written about how science, technology and mathematics education are combined in PD, however, there is limited information about including engineering design principles.

A review of the literature on effective mathematics and science PD programs points to the important relationship between providing teachers with content knowledge and subsequent changes in classroom practice. Mary Kennedy ${ }^{10}$ reviewed studies of professional development programs that documented effects of teacher PD programs on student achievement. She argued for the importance of "attending more to the content of the inservice teacher education and for attending less to its structural and organizational features."

Cohen and Hill ${ }^{11}$ examined the relationship between student achievement and high quality PD. They followed schools and teachers in three California school districts for four or five years as teachers implemented a new mathematical framework. In 1994, they surveyed 1,000 elementary mathematics teachers about their experiences. Their results point to three significant components in high quality professional development. First, professional development must help teachers understand the content they're teaching as well as the content of the standards and assessments. Second, professional development must be linked to work students are expected to do. Third, professional development must be continuous; it cannot be fragmented but rather provide consequential learning opportunities. 
In addition to providing content knowledge, other important aspects of effective professional development are described in the work of Supovitz and Turner. ${ }^{12}$ Their study provides a summary of six critical components of science professional development that have been identified by researchers and educators over the 1990's. First, high-quality professional development immerses participants in inquiry, questioning and experimentation -- and therefore, in modeled inquiry forms of teaching. Second, professional development was intensive and sustained. Third, professional development engaged the teachers in concrete teaching tasks based upon teachers' experiences with students. Fourth, professional development deepened teachers' content skills, both in subject matter knowledge and in how students learn a particular subject matter. Fifth, high quality professional development was grounded in a common set of standards and showed teachers how to connect their work to the specific standards for student performance. Sixth, reform strategies for school improvement must be connected to other aspects of school change.

Loucks-Horsley, Love, Stiles, Mundry and Hewson ${ }^{13}$ present a professional development model specifically designed for mathematics and science. The core of the model consists of a series of components including commitment to a vision and standards, analysis of student learning and other data, goal setting, planning, implementation and evaluation. Second edition augmentations include major sections on knowledge and belief systems (e.g., learners and learning, teachers and teaching, the nature of the disciplines, the change process, etc.); context (e.g., students, standards, teachers' learning needs, organizational culture, political factors, resources, community factors, etc.), critical issues (e.g., finding time for professional development activities, professional culture, capacity and sustainability issues, public support, etc.), and strategies (e.g., curriculum alignment, collaborative structures, immersion experiences, practicing teaching, etc.).

One of the most important recent studies of the effectiveness of PD is that of Garet, Porter, Desimone, Birman and Yoon ${ }^{14}$ who conducted a large-scale study of the Eisenhower Math and Science program. They relied on 1027 teachers' self-reporting to describe the experiences in a variety of PD experiences as part of the Eisenhower Program. Through this large sample, they were able to identify three core features of PD that have significant positive effect on teachers' self-reported increases in knowledge and skills and on subsequent changes in their classroom practices. The first core feature of effective PD is a clear focus on content knowledge, what teachers actually learn during PD activities about the subject matter they will be expected to teach. The second core feature of effective PD is the provision of adequate opportunities for the teachers to participate in active learning. Teachers are engaged in meaningful discussion, planning and practice including opportunities to observe expert teachers and to be observed in teaching, to plan how new curriculum materials and teaching methods will be used in the classroom, to review student work and to lead discussion and engage in written work. The third core feature of effective PD is coherence with other learning activities. Coherent PD builds on what teachers have already learned, emphasizes 
content and pedagogy aligned with national, state and local standards and supports teachers in developing sustained professional communication with other teachers who are also trying to change their teaching.

\section{Setting}

During the week of July 30, 2007, a one-week workshop was held that involved NCETE professional development providers, exemplary teachers, who had experienced one of the NCETE site-specific PD programs, beginning teachers, high school students and evaluators. The limited number of workshop participants were selected because of their willingness to reflect on their experiences in an attempt establish the characteristics of an effective PD program for high school teachers infusing engineering design concepts into a variety of STEM classrooms. The workshop focused on improving the teachers' content knowledge and instructional strategies for infusing several specific engineering design concepts (constraints, optimization and predictive analysis) into their classrooms. Teacher demographics included eight white males, three white females, one African American male, two African American females and one Hispanic female. The demographic of the professional development providers included seven white males, one African American male, one Asian male and one African American female.

The professional development workshop was guided by three goals. 1) Increase high school STEM teachers' content knowledge regarding constraints, optimization and predictive analysis in an engineering design context; 2) Increase high school STEM teachers' ability to develop, use and assess curriculum materials that addressed engineering design; and 3) Involve all participants in reflection on their experiences in order to establish the characteristics of an effective PD program for high school teachers infusing engineering design concepts into STEM classrooms. Achievement of the final goal was important to inform the planning of revisions of subsequent PD experience to be undertaken by NCETE.

Several sessions were developed to improve the teachers' understandings of the roles of constraints, optimization and analysis in engineering design. In one of the sessions, the developers asked the teachers to design a barge that would hold the most weight. The barge geometry was constrained to rectangular sides and base and was to be constructed from a 20 $\mathrm{cm}$ by $30 \mathrm{~cm}$ sheet of waterproofed paper. The teachers were introduced to concepts of buoyancy and the algebraic relationships between weight and geometry. They developed a predictive model which allowed them to optimize the weight. Teachers also fabricated and tested their designs. In another session, the developers asked the teachers to design a voltage divider for a communication problem. They were introduced to simple circuit analysis, Ohm's law and the algebraic relationships that describe the behavior of a voltage divider. The teachers designed and then tested their predicted results on breadboards. 
The workshop included a modified laboratory classroom model and modified lesson study approaches, utilizing twenty high school students ranging from freshmen through seniors. In classical lesson study, a group of teachers identifies a common goal and a content area on which to focus. To achieve their goal, the teachers worked collaboratively on a small number of lessons by planning, teaching, observing, revising and re-teaching them. Lesson study enables teachers to define their own professional development by establishing their own agendas and being their own critics. ${ }^{15}$ As Chokshi and Fernandez point out, lesson study helps build teachers' knowledge base, gets teachers out of their isolated teaching roles and provides a vehicle for collaborative and meaningful work.

The NCETE workshop used a modified lesson study approach that teamed four high school teachers together to plan a three-hour lesson that included hands-on activities. Teachers began this approach by indentifying a common goal of teaching engineering design by focusing on constraints, optimization and predictive analysis using hands-on activities. They built upon concepts they had learned earlier in designing the barge and the voltage divider. The teachers worked collaboratively on planning the lessons and re-teaching. They taught two different three-hour lessons to the students, while the rest of the professional development members were placed around the perimeter of the room observing; these activities were completed simultaneously in two different classrooms with ten students each. Once the lesson was complete, the high school students were dismissed and the four teachers discussed the lesson and activity and made changes to improve the teaching and learning approaches. The lesson was then repeated by the other two teachers teaching ten different students. Again, after the second iteration of the lesson was complete, the four teachers discussed the lesson and made any additional changes. Each of the two lessons was taught twice.

The latter part of the week was dedicated to reflection about the professional development experience. Teachers and professional developers were all involved in individual reflections as well as interactive discussions.

\section{Purpose of Evaluation}

Consistent with characteristics of a research and development project, the process is as important as eventual outcomes. Consequently, the evaluation design for the professional development program was structured to provide information across an ongoing process of design, improvement, adaptation and intentional change. This type of design is consistent with Patton's ${ }^{16}$ definition of developmental evaluation which is predicated on the understanding that perceived value of a project or activity is highly dependent on needs of a diverse group of users. Therefore, eventual users of the professional development model played an important decision-making role in goal-setting, design and prototype testing. 
The questions that guided the evaluation were:

1. How can active learning be effectively incorporated in professional development in the area of engineering design?

2. What instructional strategies do participants consider effective in an engineering design professional development program?

3. What are the barriers to infusing engineering design into existing curricula?

4. What characteristics/background should teachers have prior to attending professional development for engineering design?

5. What are design and implementation implications for engineering design professional development?

The evaluation of the summer workshop represents one of several components included in NCETE's formative evaluation for the professional development program. The results of the evaluation are being used to help guide future program evaluation workshops with teachers who have not previously been exposed to NCETE's engineering design professional development.

\section{Methodology}

\section{Evaluation Design}

The formative evaluation plan was designed to describe the developmental processes of NCETE's professional development initiative and acquire immediate feedback on select components of an engineering design professional development workshop. A mixed methods approach was chosen to obtain a richer representation of the needs and experiences of NCETE stakeholders. The data collected included written reflections completed by participating teachers and developers at the end of the workshop, an online survey for teachers and developers following the workshop and post-survey phone interviews with a select group of teachers and developers. All teachers and key developers (who were present for a minimum of three full days of the summer workshop) were asked to complete a short online survey specifically developed for their group. Interviews were conducted with key developers and with teachers who had completed the full professional development. Collecting data from key developers and teachers is not often done. Most studies, including benchmark studies such as Cohen and Hill ${ }^{11}$ and Garet, et al. ${ }^{14}$ are focused only on individual teacher self-reports. Additionally, the inclusion of qualitative methodology compliments quantitative data by offering a more meaningful and complete picture of program processes from multiple perspectives. ${ }^{17}$ Qualitative methods also assist in the identification of processes that were not considered for measurement at the beginning of an evaluation. 


\section{Written Reflections}

The teachers and developers were asked to respond to a series of questions on their workshop experience within a 30 minute time frame. The respondents were asked to incorporate prior experiences and knowledge to address the components of effective professional development. The option of responding anonymously was provided to ensure that respondents were answering the questions honestly.

\section{Online Survey}

Two online surveys were developed, one for the teachers and one for the developers, with several items used on both forms. Survey questions for both groups focused on both their experience with the summer workshop itself and sought information about the individuals' expectations of an optimal engineering design professional development program. Both groups were also asked to speak to the potential barriers in implementation of engineering design into the classroom and teacher characteristics to consider when selecting the next cohort.

The online survey was completed by ten teachers and six developers. The teachers had a mean of 9 years of teaching experience with a range from less than one year to 27 years. The teacher respondents were a diverse group, with teaching experience in math, engineering, physics, architecture, manufacturing, auto technology and electronics among other specialties.

\section{Phone Interviews}

Brief semi-structured phone interviews were completed to obtain more detailed feedback on some of the processes that occurred at the summer workshop. In particular, questions focused on the inclusion of a lesson study approach for engineering design professional development, instructional strategies and teacher selection. Questions differed slightly between the teachers and developers.

\section{Observations}

The primary author was present for the entire duration of the summer workshop and became immersed in the activities that took place. Notes were taken daily to describe the events that took place and assist in the interpretation of the results.

\section{Analysis of Data}

Reflections, open-ended survey questions and interviews were analyzed qualitatively. Each respondent's document or interview was read through by the primary author and emerging themes were documented. A theme was identified if multiple individuals (i.e., three or more) provided similar feedback that stemmed from an interview or reflection paper question. A 
second evaluator read through the documents to verify that the emerging themes fit the participant responses. Descriptive statistics were run on forced-choice questions from the online surveys. The sample size for the teachers and developers was considered to be too small to run inferential statistics.

\section{Results}

The five guiding questions presented above provide the framework for reporting the results of the workshop evaluation. As a mixed methods approach was used to collect evaluative data, all available sources of information associated with the questions are presented together.

How can active learning be incorporated into professional development in the area of engineering design?

Active learning was incorporated into the workshop through the modified lesson study model and additional reflection sessions that were held each day. Teachers appreciated and endorsed the opportunity to further develop lesson plans and teach new material shortly after learning it, the immediate feedback from students and teachers, working with students at a different level than they are accustomed to and the opportunity to witness students becoming excited about the new material. Some of the comments made by teachers included the following:

The showing, telling and being able to apply immediately. It is helpful to see different options for teaching material.

The neat part for us was that we got to see three or four different approaches to the same information because we did team up. Because we are different teachers from different areas, especially different areas of the country and different levels of kids, we got a chance to see how different master teachers deal with presenting information.

I can see somebody else who knows the subject matter and how to teach this idea at work and we can all agree that maybe there is a good, better, best way to approach the topic and then given a chance to try it and see what really works and what doesn't.

The majority of teachers thought it was highly beneficial to have the opportunity to reflect immediately after teaching with a group of students. Developers and teachers both agreed that there was great value in teachers having the opportunity to further refine an activity and teach it once again. Teachers discussed the importance of receiving feedback on their own teaching and the opportunity to observe other teachers to learn what was effective or ineffective. 
Developers' responses indicated less enthusiasm overall for the inclusion of students. However, there were some positive comments made, including the opportunity to see what teachers had taken from the lessons presented to them. One developer stated,

I liked seeing the teachers interacting with the students to see what they learned - to see how they would teach the concepts they had learned.

The concerns addressed by developers with the inclusion of students touched primarily on teacher behavior and the general setting. Some teachers were viewed as overpowering while others were perceived to be self-conscious during the teaching experience. With regard to the learning environment, one developer noted that the setting was too public and "observers were milling in and out." A summary statement made by one of the developers was,

I think it's a great method for teacher preparation and for professional development under less demanding circumstances.

The weaknesses teachers identified for the modified lesson study approach were relatively diverse. There was a desire expressed by a few of the teachers for more time to work on the lessons and more time to hear student feedback throughout the lesson.

It felt rushed - maybe break up the lessons into chunks and have critiques of the smaller chunks. Give teachers more time to work on it [lessons] and receive student feedback along the way, not just at the end of the lesson.

The issue of incompatible teaching styles amongst a group of teachers was addressed by one of the teachers. She indicated that transitioning between different teachers during the lesson did not provide the students with much consistency. Additionally, the different teaching styles could reportedly make it difficult to identify what aspects of a lesson are effective and which are not. To address this issue, the teacher followed up by recommending that shorter lessons be planned with focused topics that a teacher presents in its entirety before transitioning to another teacher. Another teacher felt that it was not very valuable to teach someone else's lesson and that she would have preferred to create her own lesson that could be tried out with students.

One teacher responded that there was too much negativity during certain aspects of the workshop that could have been prevented by presenting ground rules at the beginning of the week to help foster a supportive professional learning community. Developers voiced fewer unique concerns and focused primarily on the issue of creating an environment that most closely resembles a typical classroom for the teachers.

Teachers also took part in active reflection periods where they had opportunities to discuss how they experienced the different components of the workshop. These sessions occurred at the end of each activity and again after the final written reflection activity. Teachers indicated through the interviews and survey responses that they were appreciative of the 
opportunity to speak about their experience and hear from other teachers. One teacher commented:

Being able to reflect and have others reflect on your teaching techniques and pointing ways or point out where things might be improved. We all see ourselves one way and then others see us differently. Any time we can have someone else look at what we are doing and then critique it and give us feedback, it's helpful.

What instructional strategies do participants consider effective in an engineering design professional development program?

Analysis of the reflection papers, surveys and interviews indicated that teachers had a strong preference for experiencing activities hands on. The majority of teachers also emphasized the importance of providing content knowledge prior to engaging in an activity and providing modeling of effective instructional strategies for teaching engineering design content and activities. A teacher stated,

I think that this PD should be a balance of learning and practicing... from what I know about the nature of most tech ed teachers, they want it to be simple, very clear, it should have sort of a formula - steps to go through to implement into their school. They should be able to experiment.

Responses from the developers also focused on the benefits of integrating hands on activities into the instructional sessions. Numerous developers indicated that the warm-up or introductory activities, in particular, were key steps in getting teachers engaged and priming them for additional group work. While the teachers did not provide a specific rationale for the inclusion of the introductory activities, they did endorse bringing these activities back into their own classrooms.

Teachers reported feeling uncertain at times during the week about the goals that were associated with the activities. They desired practical goals that could be directly tied to the different activities (i.e., what specific engineering design concepts are being highlighted at the different phases of each activity).

Interestingly, nine teachers indicated on the survey that they did not see the provision of content knowledge as a priority for professional development program. However, in the reflection papers and interviews teachers expressed a need for a consistent knowledge base to draw from when learning about activities and in turn teaching those activities to students. The aggregated results of the developers indicated that four of the six developers felt that teachers should be provided with content knowledge in the area of engineering design and an average of $50 \%$ of time should be spent on providing content knowledge in a professional development program. 
There was debate among the respondents on whether or not to provide teachers with new activities or to focus on assisting teachers with infusing engineering design into their existing curricular activities. Both approaches were viewed as having merit and both may be important components for a professional development program.

A final consideration voiced primarily in the reflection papers was the importance of preparing teachers prior to their attendance at the professional development program by sending pre-workshop readings and other related material. Another way to keep teachers informed, according to respondents, is to continually tie the content and activities back to goals to ensure that teachers and developers are "on the same page."

\section{What are the barriers to infusing engineering design into existing curricula?}

The issue of barriers was considered an important area to address as NCETE continues to develop its professional development program. An understanding of experienced and expected barriers to implementing new material within an existing curriculum can assist developers in better preparing for and addressing constraints faced by teachers. Responses taken from all three data sources were used to examine the barriers that could be expected when attempting to implement engineering design into high school classrooms. The reflection papers emphasized administrative barriers, curricular and content issues, teacher buy-in and teacher background knowledge and skills. Online survey results found that teachers listed student abilities or preconceptions, curricular or administrative restrictions, time and money as the most significant barriers to infusing engineering design into their classrooms. With a smaller sample size for the developer there was greater distribution of responses focusing on barriers. The barriers listed included variations in teacher backgrounds, numerous unknowns in developing an engineering design professional development model, difficulty in obtaining buy-in from state and district administration and competing demands for those involved with the development and implementation of professional development. A developer commented that,

Infusing engineering design takes practice and time. Practice in small pieces, then [take] time to weave it into existing local/geographic curriculums and programs with the help of other teachers and guidance or teacher educator and PDs (who may also be teachers).

Barriers addressed in the reflection papers focused on the diversity in technology education between regions and schools and in goals across different technology education teachers and subjects. A theme that emerged surrounding these concerns was the need for engaging in an ongoing dialogue with teachers across multiple sites to better determine what is feasible across districts/regions. In addition, concerns were expressed in relation to motivating teachers enough to implement the content and activities in their classrooms, time constraints for teachers, group cohesiveness and limited teacher knowledge. 
What characteristics/background should teachers have prior to attending professional development for engineering design?

In the end-of-workshop reflection papers, many respondents emphasized the importance of developer awareness of the backgrounds of the teachers entering the professional development program. This was in part so the content presented in professional development was designed to fit with the different classroom approaches (i.e., project oriented or more process oriented) and teacher strengths and weaknesses. There were several differences between what teachers and developers considered to be important characteristics for teachers taking part in engineering design professional development. The majority of teachers reported the need for a minimal level of mathematical and science aptitude. Developers were less concerned overall with teacher participants' levels of mathematics and science aptitude. Developers expressed greater concern about teacher credentials, licensure and certification. One area of agreement between teachers and developers was on the importance of selecting motivated teachers who are open to new approaches and content. Comments related to this finding included "a willingness to think outside of their expertise" and "a willingness to learn."

Teachers who participated in the interviews went beyond disciplinary aptitude to emphasize other characteristics such as interest level, willingness to change and innovativeness. Developers highlighted similar characteristics including "open-mindedness" and an interest in engineering design. The need for strong academic abilities in the areas of mathematics was mentioned but there was recognition that professional development should provide the necessary math skills that match up with the new content and activities.

What are design and implementation implications for engineering design professional development?

The workshop brought up additional issues to consider when organizing a professional development program. For instance, a common concern was how to design a program for a diverse teacher population. Teachers and developers acknowledged that different schools and districts have different standards and curricula guidelines for teachers to follow, a situation that could result in limited opportunities for teachers to incorporate new content knowledge or activities into their classrooms.

Although the teachers were excited about participating in hands on activities, they felt a need to spend additional time on defining engineering design prior to beginning activities. A related issue to defining engineering design was the need to describe what engineering design look like in a high school classroom. This would include specific information about what types of classes engineering design could be incorporated into, and the characteristics of activities that could be easily recognized as incorporating engineering design principles. 
One respondent wrote in their reflection paper that "consistency between verbalized goals and actions [is needed]."

Teachers communicated through the reflection papers and through the interviews that they desired a focus on a well-developed and overarching guide, such as constraints, optimization and predictive analysis to familiarize themselves with prior to, and during, hands on activities. Without consistent, overarching guides teachers believed it possible to become confused by what engineering design is and how to apply it to activities in their own classrooms. It was also suggested that any professional development approach focus on content knowledge in the areas of math and science that are likely to be included in engineering design problems.

Developers and teachers recognized the challenge of creating a professional development program that could reach a broad audience of teachers (i.e., differing math and science backgrounds, curriculum goals and instructional skills). To better prepare for diverse groups of teachers many respondents suggested giving an initial assessment prior to the start of professional development to help the developers prepare for the different backgrounds of teachers. Additionally, it was suggested that there be a focus on assisting teachers with taking existing activities and incorporate engineering design into those activities.

To promote the implementation of engineering design content and activities in the teacher's home classrooms a teacher team approach is suggested by the workshop. Teachers found the input from their peers valuable and motivating. In addition, support from other teachers, including through networking across school districts was endorsed through the survey and reflection papers.

Including students in professional development activities was highly endorsed by the teachers though shortcomings were also recognized. These shortcomings include the need to increase student diversity and increase student presence at the workshops. Developers indicated through the reflection papers and the interviews that the logistical problems surrounding the inclusion of a representation sample of students in professional development may be too great of an impediment to justify a strong recommendation for this approach. On the other hand, developers were forthcoming about the benefit of observing teachers teach engineering design content and activities.

\section{Conclusion}

The focus of the evaluation design for the professional development program was to describe and inform current practices and future program decisions. At the time of the evaluation there was a paucity of published literature addressing the process of developing a PD program in engineering design. It was therefore considered imperative to closely examine the different components being considered for inclusion into a revised PD program from a variety of perspectives. The key NCETE developers played an important role in developing 
evaluation goals with the evaluation team. The mixed methods approach employed provided NCETE developers with a rich repository of information to inform future PD program decisions. Triangulation of data led to increased validity in the reported results of the evaluation and to the identification of discrepancies that require further inquiry (i.e., the inclusion of students in professional development).

Associated with the need to understand the essential engineering concepts and skills that students should master is the importance of developing a clearer understanding of needed teacher content knowledge. The teachers selected to participate in the workshop had opportunities to infuse engineering design content into their curriculum prior to the workshop, whether through technology education, pre-engineering, mathematics or science classes. The teachers had a variety of STEM backgrounds and their responses reflected this diversity - they wanted PD designed to fit a variety of classroom approaches and teacher strengths and weaknesses. The majority of teachers endorsed a minimal level of mathematical and science skill. Developers were less concerned overall with the level of mathematics and science skills that a teacher had. They felt greater attention should be given to the general credentials of a teacher (i.e., licenses, teaching certificates). In addition to understanding necessary teacher content knowledge, there is a need to describe the pedagogical content knowledge required to effectively teach engineering to diverse student populations.

The evaluation results provide tentative support that designing engineering PD could be informed by the findings of the mathematics and science education community. Teachers' favorable comments about modified lesson study and the reflection session as important components of active learning align with the findings of Garet, et al. ${ }^{14}$ Teachers noted implementation barriers associated with curricular and administrative restriction. They were very concerned about what was feasible within their own district, consistent with the findings of Garet, et al. and Supovitz and Turnver ${ }^{12}$ and the need for coherence in PD. In the reflection papers and the interviews, teachers expressed a need for a consistent knowledge base to draw from when learning about activities. Teachers noted enthusiasm for participating in hands on activities but also expressed a need to spend additional time understanding engineering design prior to teaching the activities. Interestingly, the online survey results indicated that teachers did not see content knowledge as a priority for PD, perhaps suggesting that teachers did not clearly understand the term "content knowledge." The preponderance of evaluation results or other studies indicate teachers are highly interested in improving their content knowledge.

There are a few notable limitations for the professional development evaluation. The primary limitation of the evaluation was the small number of participating teachers and developers. The small sample size limited the quantitative analyzes that could take place. Additionally, disaggregation of teacher and developer groups was not possible (i.e., novice teachers and experienced teachers). The interviews and online survey did not occur until approximately 
one month following the workshop. As a result of the passage of time there may have been a recall bias for the participants that impacted the feedback provided in the interviews and survey.

The outcomes from the professional development workshop evaluation highlighted the importance of continuing to incorporate a mixed methods approach to enhance the validity of the evaluation. Furthermore, the inclusion of a qualitative component greatly enhanced the understanding of the teacher and developer experiences and provided valuable information on effective and ineffective processes that took place during the workshop. The evaluators will continue to work closely with the developers in the creation of evaluation questions and evaluation instruments that are tied to the goals of the program and enhance the development of NCETE's professional development program.

\section{Acknowledgement}

This material is based on work supported by the National Science Foundation under Grant Number ESI-0426421. The opinions expressed are those of the authors.

\section{References}

[1] American Association for the Advancement of Science. (1993). Benchmarks for science literacy. New York: Oxford University Press.

[2] International Technology Education Association. (2000). Standards for technological literacy, Content for the study of technology. Reston, VA: Author.

[3] Merrill, C., Childress, V., Rhodes, C., \& Custer, R. (2006). Infusing engineering concepts into technology education. Paper presented at the American Society for Engineering Education Annual Conference and Exposition, Chicago, IL.

[4] Merrill, C., Custer, R., Daugherty, J., Westrick, M., \& Zeng, Y. (2007). Delivering core engineering concepts to secondary level students. Paper presented at the American Society for Engineering Education Annual Conference and Exposition, Honolulu, HI.

[5] Shumway, S., Berret, J., Swapp, A. G., Erekson, T. L., \& Terry, R.E. (2007). A successful professional development activity to infuse engineering content for Utah 9-12 teachers. Paper presented at the American Society for Engineering Education Annual Conference and Exposition, Honolulu, HI.

[6] Tufenkjian, M. \& Lipton, E. B. (2007). Professional development model to infuse engineering design content into the high school curriculum. Paper presented at the American Society for Engineering Education Annual Conference and Exposition, Honolulu, HI.

[7] Hailey, C., Erekson, T., Becker, K., \& Thomas, M. (2005). National Center for Engineering and Technology Education. The Technology Teacher. 64(5) 23-26. 
[8] Lewis, T. (2005). Coming to terms with engineering design as content. Journal of Technology Education, 16(2), 34-51.

[9] Lewis, T. (2007). Engineering education in the schools. International Journal of Engineering Education, 23(5), 843-852.

[10] Kennedy, M. (1998). Form and substance in inservice teacher education, National Institute for Science Education. Research Monograph No. 13.

[11] Cohen, D.K. \& Hill, H.C. (1998). State policy and classroom performance: Mathematics reform in California. Washington, DC: Consortium for Policy Research in Education.

[12] Supovitz, J.A. \& Turner, H. M. (2000). The effects of professional development on science teaching practices and classroom culture. Journal of Research in Science Teaching, 37(9), 963-980.

[13] Loucks-Horsley, S., Love, N., Stiles, K. E. Mundry, S., \& Hewson, P. W. (2003). Designing professional development for teachers of science and mathematics. Thousand Oaks, CA: Corwin.

[14] Garet, M., Porter, A.C., Desimone, L., Birman, B.F., \& Yoon, K. W. (2001). What makes professional development effective? Results from a national sample of teachers. American Educational Research Journal, 38(4). 915-945.

[15] Chokshi, S. \& and Fernandez, C. (2005). Reaping the systemic benefits of lesson study: Insights from the U.S, Phi Delta Kappan, 86(9), 674-680.

[16] Patton, M. Q. (1994). Developmental evaluation. Evaluation Practice, 15(3), 311-319.

[17] Weiss, C.H. (1988). Evaluation, Second Edition. Upper Saddle River, NJ: Prentice-Hall. 